\title{
BMJ Open Improving the governance of patient safety in emergency care: a systematic review of interventions
}

\author{
Gijs Hesselink, ${ }^{1,2}$ Sivera Berben, ${ }^{1,3}$ Thimpe Beune, ${ }^{1}$ Lisette Schoonhoven ${ }^{1,2,4}$
}

To cite: Hesselink G, Berben S, Beune T, et al. Improving the governance of patient safety in emergency care: a systematic review of interventions. BMJ Open 2016;6:e009837. doi:10.1136/bmjopen-2015009837

- Prepublication history and additional material is available. To view please visit the journal (http://dx.doi.org/ 10.1136/bmjopen-2015009837).

Received 26 August 2015 Revised 2 November 2015 Accepted 30 November 2015

CrossMark

For numbered affiliations see end of article.

\section{Correspondence to}

Dr Gijs Hesselink; gijs.hesselink@radboudumc. $\mathrm{nl}$

\section{ABSTRACT}

Objectives: To systematically review interventions that aim to improve the governance of patient safety within emergency care on effectiveness, reliability, validity and feasibility.

Design: A systematic review of the literature.

Methods: PubMed, EMBASE, Cumulative Index to Nursing and Allied Health Literature, the Cochrane Database of Systematic Reviews and PsychInfo were searched for studies published between January 1990 and July 2014. We included studies evaluating interventions relevant for higher management to oversee and manage patient safety, in prehospital emergency medical service (EMS) organisations and hospital-based emergency departments (EDs). Two reviewers independently selected candidate studies, extracted data and assessed study quality. Studies were categorised according to study quality, setting, sample, intervention characteristics and findings.

Results: Of the 18 included studies, 13 (72\%) were non-experimental. Nine studies $(50 \%)$ reported data on the reliability and/or validity of the intervention. Eight studies $(44 \%)$ reported on the feasibility of the intervention. Only 4 studies (22\%) reported statistically significant effects. The use of a simulation-based training programme and well-designed incident reporting systems led to a statistically significant improvement of safety knowledge and attitudes by ED staff and an increase of incident reports within EDs, respectively.

Conclusions: Characteristics of the interventions included in this review (eg, anonymous incident reporting and validation of incident reports by an independent party) could provide useful input for the design of an effective tool to govern patient safety in EMS organisations and EDs. However, executives cannot rely on a robust set of evidence-based and feasible tools to govern patient safety within their emergency care organisation and in the chain of emergency care. Established strategies from other high-risk sectors need to be evaluated in emergency care settings, using an experimental design with valid outcome measures to strengthen the evidence base.

\section{INTRODUCTION}

Executives of healthcare services are increasingly held accountable for patient safety. ${ }^{12}$ Therefore, they have a fundamental

\section{Strengths and limitations of this study}

This is the first systematic review of the literature that has evaluated the effects, reliability, validity and feasibility of interventions aimed to improve the governance of patient safety (ie, the ability for higher management to monitor and manage patient safety) in emergency care settings.

- The review provides an overview of a variety of promising tools and their characteristics to monitor and manage patient safety in various types of emergency medical service organisations and in emergency departments. However, robust evidence to support these tools is absent.

- The small number of included studies and the heterogeneity in the selected studies in terms of design, aims, intervention activities, population samples and presented outcomes make generalisations difficult.

- To date, no studies have examined the effectiveness of interventions aimed to improve the governance of patient safety in the chain of emergency care, nor have they evaluated their psychometric properties and feasibility.

governance role in overseeing and managing safety risks within their service. ${ }^{3}$ Governance of patient safety is especially important in the field of emergency care, because emergency care involves high patient safety risks. Care is often delivered to high-acuity patients with unstable vital signs in a fast-paced setting under unpredictable conditions. ${ }^{4}$ Also, emergency care often involves collaboration between different emergency medical service (EMS) organisations, including: general practitioner out-of-hours services (GP OHS), ambulance EMS, helicopter EMS (HEMS) and psychiatric EMS, and between EMS organisations and the emergency department (ED) in the hospital. Frequent patient handovers between the different services involve inherent opportunities for miscommunication and adverse events (AEs) to occur. ${ }^{5-7}$

Executives of emergency care organisations, however, seem to fall short in the governance of patient safety. Evidence shows 
that suboptimal emergency care is an important cause of patient harm and mortality. Between $6 \%$ and $8.5 \%$ of the patients who receive care in the ED experience an AE. ${ }^{89}$ Furthermore, $36-71 \%$ of the AEs in the ED are believed to be preventable. ${ }^{10}$ Preventable AEs also occur in ambulance EMS, HEMS and GP OHS. ${ }^{1-13}$ Causes of AEs relate to system failures, stressed and fatigued care providers, medication errors, communication problems, lack of professional skills and problems with medical equipment. ${ }^{1415}$

Several studies investigated board engagement with quality and safety issues in their health service, ${ }^{16}{ }^{17}$ and systematically reviewed the effectiveness and usefulness of governance systems and tools. ${ }^{18}{ }^{19}$ However, evidence on effective safety governance activities in emergency care is unknown. More insight into available valid, reliable and feasible means to monitor and manage safety risks could provide boards better oversight of patient safety and accountability of their emergency care organisation, and the chain of emergency care. We defined the chain of emergency care as: the interprofessional structure in which emergency care is delivered by multiple providers with the aim to provide seamless care to patients with acute care needs. ${ }^{6}$

The purpose of this study is to systematically review interventions aimed at improving the governance of patient safety in (the chain of) emergency care, and to evaluate their effects, reliability, validity and feasibility.

\section{METHODS}

We planned and reported this systematic review in accordance with the guideline for performing and reporting systematic reviews and meta-analyses (PRISMA, Preferred Reporting Items for Systematic Reviews and Meta-Analyses).$^{20}$

\section{Data sources and searches}

We searched for English and Dutch language studies published between January 1990 and July 2014 in the following databases: PubMed (including MEDLINE), Cumulative Index to Nursing and Allied Health Literature (CINAHL), Embase, PsychInfo and the Cochrane Library. Online supplementary appendix 1 provides a detailed listing of the search terms. We also searched for additional relevant studies (ie, 'snowballing'): (1) via Google with the use of major key terms (ie, 'governance' AND 'emergency care' AND 'patient safety'); (2) by reviewing references from the included studies and (3) by reviewing online archives/ bibliographies of three high-impact journals in the field of emergency care (Annals of Emergency Medicine, Injury, Journal of Trauma and Acute Care Surgery).

\section{Study selection}

Two reviewers (GH and $\mathrm{SB}$ ) independently screened the titles and abstracts of all studies identified by the search strategy for their eligibility. For inclusion, each study had to meet four criteria: (1) experimental or non-experimental study published as a full-text article or dissertation, (2) evaluating an intervention aimed at improving the governance of patient safety (ie, the ability for higher management to monitor and manage patient safety); (3) within the emergency care setting and (4) reporting data on the effect, validity, reliability or feasibility in terms of time and cost investment, and user friendliness of the intervention. Studies with a focus on acute dental care, intensive care (IC) and disaster medicine were excluded. When the title and abstract did not clearly indicate whether the inclusion criteria were met, a full-text copy was retained and reviewed.

Full-text copies of the potentially relevant studies were retrieved and evaluated for inclusion as described previously by two reviewers ( $\mathrm{GH}$ and $\mathrm{TB}$ ). A final set of studies was identified for data extraction. Inclusion discrepancies were reconciled by discussion.

\section{Data extraction}

GH and TB independently extracted data from each study meeting the inclusion criteria. A standardised form was used to ensure consistency of data extracted from each article. The extracted data described the study objectives, underlying theory-based concepts, setting, sample, intervention characteristics and findings. Disagreement between the reviewers was resolved by discussion. If no consensus was reached, a third reviewer (SB) was consulted.

\section{Quality assessment}

GH and TB independently assessed the study quality using a quality appraisal tool developed by Kmet $e t a l^{21}$ Studies were scored on up to 24 items: 14 items for studies with a quantitative research design and 10 items for studies with a qualitative research design. Items were scored depending on the degree to which the specific criteria were met ('yes'=2, 'partial' $=1$, 'no'=0). Items not applicable to a particular study design were marked 'NA' and were excluded from the calculation of the summary score. Discrepancies were resolved through discussion. If no consensus was reached, a third reviewer (SB) was consulted. A study quality score (percentage) was calculated for each paper by summing the total score obtained across relevant items and dividing the obtained score by the total possible score.

\section{Data synthesis}

Study outcomes were organised in tabular form and a classification was made based on the study design, setting, sample size, intervention characteristics and outcomes, namely: effects and reported statistical significance, psychometric properties (ie, reliability and validity) and feasibility of the intervention.

\section{RESULTS}

\section{Search results}

Our initial search identified 4287 records. After exclusion of duplicates, 3713 records were screened by title and abstract. Seventy full-text studies were retrieved and reviewed, of which 57 were excluded. Five articles were 
identified through snowballing. The final set consisted of 18 published studies that underwent full-text extraction (figure 1). Owing to the heterogeneity of the study designs, participants and outcome measures, a meta-analysis of the results was not possible.

\section{Study quality}

Thirteen articles had a quantitative study design. ${ }^{22-34}$ Two articles had a qualitative study design. ${ }^{35} 36$ Three articles combined both quantitative and qualitative methods. ${ }^{37-39}$ The study quality scores ranged between $41 \%$ and $100 \%$ (tables 1 and 2). Two articles scored low (ie, <55\%), ${ }^{32} 34$ 10 articles scored high (ie, $>75 \%$ ), ${ }^{23-28} 303133361$ article scored high on the qualitative study and low on the quantitative study part, ${ }^{38} 1$ article scored high on the quantitative study and moderate on the qualitative study part, ${ }^{39}$ and 1 other article scored high on both (qualitative and quantitative) study parts. ${ }^{37}$ The three remaining studies scored a moderate in-between rating. ${ }^{22} 2935$ Of the five articles with qualitative research, four had no or an unclear qualitative data analysis description (eg, omitting the types of analysis). Three qualitative studies failed to fully describe their qualitative data collection methods (eg, not mentioning an interview guide or the number of consensus rounds conducted in a Delphi study). ${ }^{35} 3839$ Three qualitative studies showed no or poor use of verification procedures to establish credibility. ${ }^{35} 3639$ Compared with the qualitative studies, the quantitative studies lacked in points related to sampling. Of the 16 articles with quantitative research, 8 had no or poor description of their sampling strategy (eg, inclusion and exclusion criteria), ${ }^{22-24} 29$ 32-34 38 lacked an appropriate sample size $e^{23-26} 32 \quad 34 \quad 37 \quad 38$ and described sample characteristics insufficiently. ${ }^{25}$ 28-30 33 35-37 Only two articles with quantitative research reported to appropriately control for confounding variables. ${ }^{28} 31$

\section{Study characteristics}

Table 3 shows a summary of the study characteristics. A more detailed overview of the study characteristics is provided in online supplementary appendix 2 . Of the 18 included studies, $10(56 \%)$ were performed in the USA, ${ }^{26} 2730-3537394(22 \%)$ in Australia, ${ }^{22-24} 282$ (11\%) in the Netherlands, ${ }^{25}{ }^{29} 1(6 \%)$ in the $\mathrm{UK}^{38}$ and $1(6 \%)$ in Canada. ${ }^{36}$ Thirteen studies $(72 \%)$ were non-experimental. Five studies $(28 \%)$ were quasi-experimental using an interrupted time series design, ${ }^{30} 33$ a non-equivalent group design ${ }^{28} 29$ and a before-after design. ${ }^{22}$

Of the 18 included studies, $12(67 \%)$ evaluated a safety governance intervention within EDs, ${ }^{22-25} \quad 28 \quad 30-34 \quad 36 \quad 38$ 4 (22\%) within EMS organisations, ${ }^{26} 2735391$ within an HEMS $^{37}$ and 1 (6\%) within GP OHS. ${ }^{29}$ One study focused on monitoring the quality and safety of ambulance and HEMS collaboration. ${ }^{39}$ The sample size ranged from 60 to 1595 studied care providers, 6858-211 321 studied patients and 47-20 050 studied files (eg, incident reports, medical records, claim files). One study (6\%) described a study panel of 10 expert clinicians as the study sample. ${ }^{33}$
Four studies (22\%) reported statistically significant effects. $^{22} 283033$ Nine studies (50\%) reported data on the reliability and/or validity of the intervention. ${ }^{23} 25-2735-39$ Eight studies (44\%) reported on the feasibility of the intervention. ${ }^{23-26} 29313336$

\section{Intervention characteristics and findings}

Six studies (33\%) examined methods for screening and assessing AEs, incidents and patient deaths. ${ }^{22-25} 3537$ Four studies $(22 \%)$ evaluated safety culture and care provider behaviour measures. ${ }^{26} 2738{ }^{39}$ Three studies $(17 \%)$ evaluated incident reporting systems. ${ }^{28-30}$ Two studies $(11 \%)$ evaluated patient safety indicators. ${ }^{31} 36$ Two studies (11\%) evaluated training methods for improving care provider safety skills and attitudes. ${ }^{32} 33$ One study $(6 \%)$ evaluated the effectiveness of Patient Safety Walk-rounds (PSWs). ${ }^{34}$

\section{Screening and assessment methods}

Four studies described methods to screen and assess AEs. Wolff and Bourke ${ }^{22}$ described retrospective screening of medical records in the $\mathrm{ED}$ with the use of an $\mathrm{AE}$ severity scale to assess AEs. A clinical risk manager performed the screening and assessment of AEs, and created weekly reports for the ED management, describing the type and severity of identified AEs and improvement actions. Aggregated quarterly reports detailing actions taken and $\mathrm{AE}$ rates were presented to the hospital's main quality improvement committee. In addition, uniform reporting of incidents by ED staff was stimulated with the use of one definition of a clinical incident and a standardised incident report form. Over 2 years, the number of AEs reduced-a relative risk reduction of $85.3 \%$ (95\% CI $62.7 \%$ to $100 \%$ ). Hendrie et al ${ }^{23}$ evaluated an $\mathrm{AE}$ screening and assessment method of case records. AEs were identified using a validated data collection instrument and classified on management causation, outcome and preventability. Inter-rater agreement on the classification of AEs $(\mathrm{K}=0.15)$, on judgements about management causation $(\mathrm{K}=0.50)$ and on preventability $(\mathrm{K}=0.58)$ was poor. Furthermore, the researchers considered the time to detect an $\mathrm{AE}$ to be substantial. The study did not report any measure of effect (eg, regarding the number of detected AEs). Patterson et a $\hat{l}^{55}$ evaluated a method for $\mathrm{AE}$ identification and severity rating in medical charts in ambulance EMS. A definition of an $\mathrm{AE}$ in $\mathrm{EMS}$ and an $\mathrm{AE}$ severity-rating index were developed in a consensus study for uniform identification of AEs in medical charts. Multirater agreement on classification of AEs was poor $(\mathrm{k}=0.24)$. Patterson et $a \hat{l}^{77}$ used a modified Delphi study to develop a consensusbased $\mathrm{AE}$ definition and a framework for $\mathrm{AE}$ detection in HEMS. Subsequently, the framework evaluated on content validity, using the item and scale content validity index. The framework was composed of three main components: (1) a trigger tool to operationalise $\mathrm{AE}$ detection, using key words or phrases contained within patient care reports that have a high probability of being 


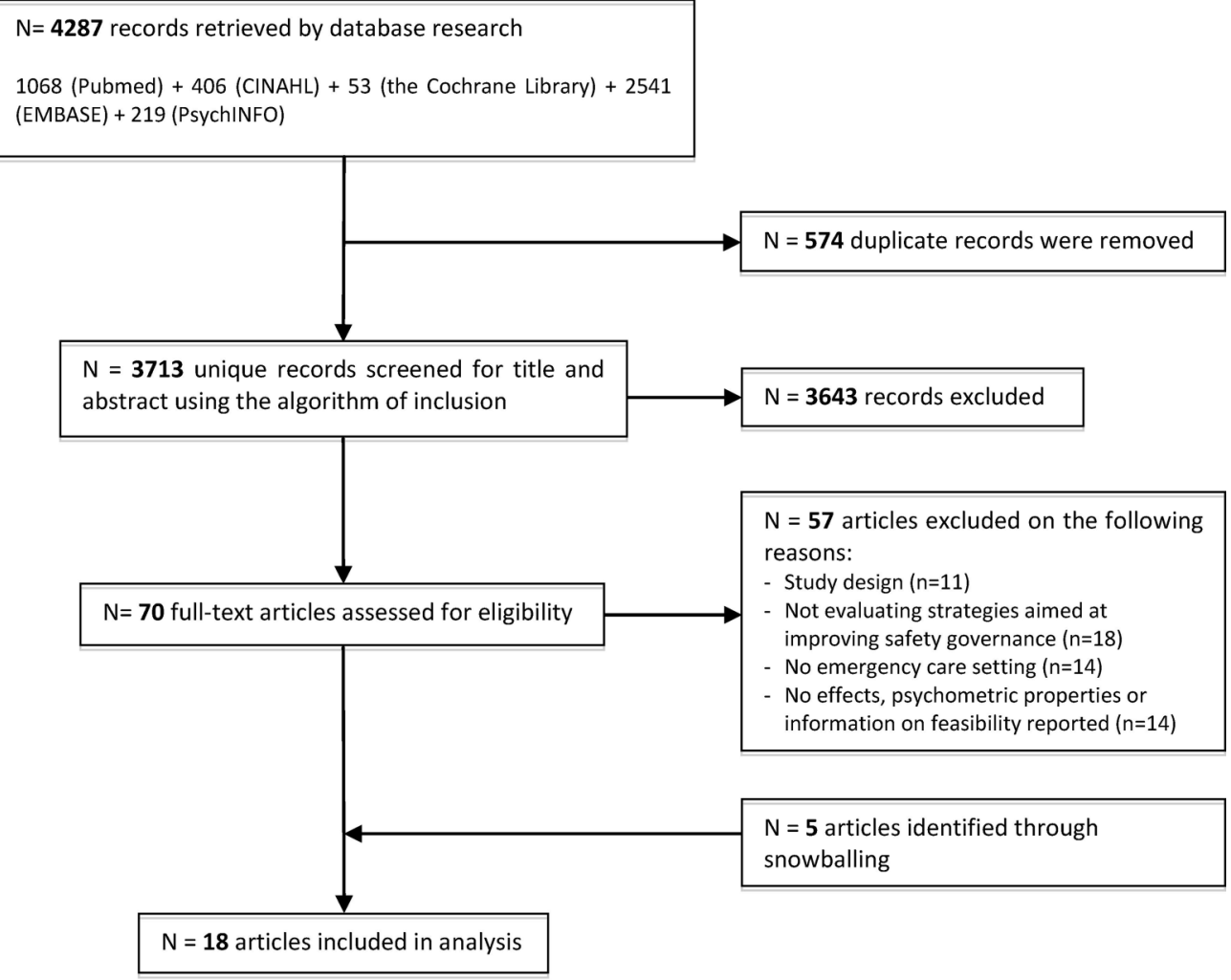

Figure 1 Flow chart of the study selection and review process.

linked to patient harm, (2) a method for rating $\mathrm{AE}$ severity, (3) a method for rating proximal cause of AEs. All three components of the framework showed content validity. The study did not report any measure of effect.

Clunas $e t a l^{24}$ evaluated an audit of patient deaths that occurred within $48 \mathrm{~h}$ of ED presentation in addition to auditing all deaths that occurred in the ED itself. The authors tested the audit by reviewing 303 deaths, including 75 deaths in the ED and 228 deaths within $48 \mathrm{~h}$ of ED presentation. Results showed that $36 \%$ of the death cases within $48 \mathrm{~h}$ of ED presentation that required a major external hospital review were not identified by the standard hospital incident monitoring system.

The psychometric properties and the feasibility of the Prevention and Recovery Information System for Monitoring and Analysis (PRISMA) was evaluated by van Noord $e t a l^{25}$ to retrospectively analyse root causes of incidents that have led to malpractice claim files in the ED. The authors found a high inter-rater agreement on classification of root causes $(\mathrm{K}=0.78)$. Validity of the root cause profile of claims was considered moderate. The delay between incident occurrences and their detection and reporting made it difficult to draw firm conclusions from the analyses. Finally, the PRISMA analyses were time consuming. The study did not report any measure of effect.

\section{Safety culture and care provider behaviour measures}

Patterson et $a l^{26} 27$ evaluated the Safety Attitudes Questionnaire (SQA). The EMS-SQA is a modified version of the validated Intensive Care Unit SAQ
(ICU-SAQ). The anonymised questionnaire is administered in paper form and/or via the internet. Respondents are asked to rate 60 items on a five-point Likert scale (strongly agree to strongly disagree). The responses are used to characterise six safety domains (eg, safety climate and teamwork climate). Evaluation of the six safety domains, using Confirmatory Factor Analysis (CFA), revealed acceptable internal consistency and model fit validity of the EMS-SQA. Patterson $e t a l^{26}$ confirmed feasibility of the EMS-SQA based on the high response rate and positive feedback on instrument utility from EMS chief administrators. In contrast, the authors stated that some chief administrators raised concerns about the respondent burden and the face validity of several questionnaire items. The study did not report any measure of effect.

Flowerdew $e t a l^{38}$ evaluated a method to assess care provider non-technical skills in the ED. A behavioural marker system was developed for the observational assessment of 12 specific non-technical skills required by physicians, for example, maintaining standards, managing workload and resolving conflict. Skills were assessed on a nine-point rating scale and divided into 'unacceptable', 'acceptable' and 'exemplary'. The tool was considered to be valid based on the input of evidence-based literature, and the input of interviews with staff and observations, to determine whether, in practice, the skill list contained any significant omissions and whether skills were observable. A survey among experts proved content validity of the developed list of 
Table 1 Quality assessment of studies with quantitative design

\begin{tabular}{|c|c|c|c|c|c|c|c|c|c|c|c|c|c|c|c|c|}
\hline & $\begin{array}{l}\text { Wolff } \\
\text { and } \\
\text { Bourke }^{22} \\
\end{array}$ & $\begin{array}{l}\text { Hendrie } \\
\text { et } a \text { P }^{3}\end{array}$ & $\begin{array}{l}\text { Patterson } \\
\text { et } a \beta^{37 \star}\end{array}$ & $\begin{array}{l}\text { Clunas } \\
\text { et } a P^{4}\end{array}$ & $\begin{array}{l}\text { van } \\
\text { Noord } \\
\text { et } a P^{5}\end{array}$ & $\begin{array}{l}\text { Patterson } \\
\text { et } a P^{6}\end{array}$ & $\begin{array}{l}\text { Patterson } \\
\text { et } a P^{7}\end{array}$ & $\begin{array}{l}\text { Flowerdew } \\
\text { et } a \beta^{38 *}\end{array}$ & $\begin{array}{l}\text { Jaynes } \\
\text { et } a \beta^{\beta *}\end{array}$ & $\begin{array}{l}\text { Evans } \\
\text { et } a P^{8}\end{array}$ & $\begin{array}{l}\text { Zwart } \\
\text { et } a \text { P }^{9}\end{array}$ & $\begin{array}{l}\text { Reznek and } \\
\text { Barton }^{30}\end{array}$ & $\begin{array}{l}\text { Pham } \\
\text { et } a^{\beta 1}\end{array}$ & $\begin{array}{l}\text { Jones } \\
\text { et } a \boldsymbol{p}^{32}\end{array}$ & $\begin{array}{l}\text { Patterson } \\
\text { et } a \beta^{33}\end{array}$ & $\begin{array}{l}\text { Shaw } \\
\text { et } a \beta^{34}\end{array}$ \\
\hline $\begin{array}{l}\text { Question/objective } \\
\text { sufficiently } \\
\text { described? }\end{array}$ & 2 & 2 & 2 & 1 & 2 & 2 & 1 & 1 & 2 & 2 & 2 & 2 & 2 & 2 & 2 & 2 \\
\hline $\begin{array}{l}\text { Study design } \\
\text { evident and } \\
\text { appropriate? }\end{array}$ & 2 & 1 & 2 & 2 & 2 & 2 & 2 & 1 & 2 & 2 & 2 & 2 & 2 & 2 & 2 & 1 \\
\hline $\begin{array}{l}\text { Method of subject/ } \\
\text { comparison group } \\
\text { selection or source } \\
\text { of information/input } \\
\text { variables described } \\
\text { and appropriate? }\end{array}$ & 1 & 1 & 2 & 0 & 2 & 2 & 2 & 1 & 2 & 2 & 1 & 2 & 2 & 1 & 1 & 1 \\
\hline $\begin{array}{l}\text { Subject } \\
\text { characteristics } \\
\text { sufficiently } \\
\text { described? }\end{array}$ & 2 & 2 & 2 & 1 & 2 & 2 & 1 & 1 & 1 & 2 & 2 & 1 & 2 & 1 & 1 & 1 \\
\hline $\begin{array}{l}\text { If interventional and } \\
\text { random allocation } \\
\text { was possible, was it } \\
\text { described? }\end{array}$ & NA & NA & NA & NA & NA & NA & NA & NA & NA & 2 & 0 & NA & NA & 1 & NA & NA \\
\hline $\begin{array}{l}\text { If interventional and } \\
\text { blinding of } \\
\text { investigators was } \\
\text { possible, was it } \\
\text { reported? }\end{array}$ & 0 & NA & NA & NA & NA & NA & NA & NA & NA & 2 & NA & NA & NA & NA & 2 & NA \\
\hline $\begin{array}{l}\text { If interventional and } \\
\text { blinding of subjects } \\
\text { was possible, was it } \\
\text { reported? }\end{array}$ & 0 & NA & NA & NA & NA & NA & NA & NA & NA & 2 & NA & NA & NA & NA & NA & NA \\
\hline $\begin{array}{l}\text { Outcome and } \\
\text { exposure measure } \\
\text { (s) well defined and } \\
\text { robust to } \\
\text { measurement/ } \\
\text { misclassification } \\
\text { bias? Means of } \\
\text { assessment } \\
\text { reported? }\end{array}$ & 2 & 2 & 1 & 2 & 1 & 2 & 2 & 1 & 1 & 2 & 2 & 2 & 2 & 1 & 1 & 1 \\
\hline $\begin{array}{l}\text { Sample size } \\
\text { appropriate? }\end{array}$ & 2 & 1 & 1 & 1 & 1 & 1 & 2 & 1 & 2 & 2 & 2 & 2 & 2 & 0 & 2 & 1 \\
\hline $\begin{array}{l}\text { Analytic methods } \\
\text { described/justified } \\
\text { and appropriate? }\end{array}$ & 1 & 2 & 2 & 2 & 2 & 2 & 1 & 1 & 1 & 2 & 2 & 2 & 2 & 2 & 2 & 0 \\
\hline
\end{tabular}




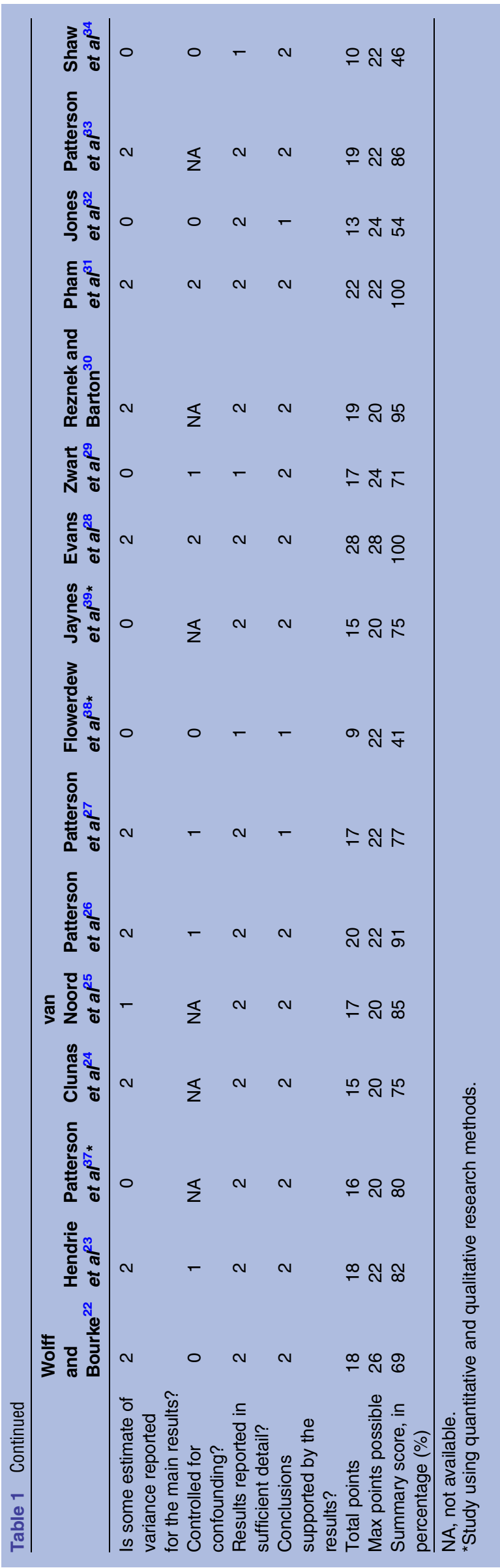

skills and behavioural markers. The study did not report any measure of effect.

Jaynes $e t a l^{9}$ evaluated an instrument to assess the working relationship between ambulance and HEMS care providers. The questionnaire consisted of 22 items that were rated on a five-point Likert scale (never/very poor to always/very good). The questionnaire was developed based on the input of providers, medical directors and administrators $(n=12)$, who defined the activities involved in the EMS-HEMS working relationship and generated items (eg, We have the information we need for making transport decisions). HEMS and EMS personnel reviewed the questionnaire and determined content validity based on consensus. The measure had good internal reliability, with a Cronbach's $\alpha$ for each domain varying between 0.85 and 0.88 . Explanatory factor analysis showed that a single underlying factor could best account for all questionnaire items. The study did not report any measure of effect.

\section{Incident reporting systems}

Evans $e t a l^{28}$ evaluated an incident reporting programme in the ED. The programme included the display of posters and manuals for staff describing the importance of reporting, the possibility of anonymous reporting, the use of a one-page report form, a $24 \mathrm{~h} / 7$ days open telephone reporting service, and feedback on statistics and root-cause analysis findings to all ED staff. A patient safety manager initially assessed incident reports. Also, anonymous reports were validated and managed without the involvement of unit heads. The intervention resulted in a statistically significant improvement in reporting by the ED staff; an overall increase of 39.5 incident reports per $10000 \mathrm{ED}$ attendances $(95 \%$ CI 17.0 to 62.0 ; $\mathrm{p}<0.001)$. Zwart $e t a l^{29}$ compared a local incident reporting procedure (LIRP) with a centralised incident reporting procedure (CIRP) in Dutch GP OHS. In the LIRP, a local multidisciplinary committee is trained to screen and analyse incident reports, whereas in the CIRP, incident analysis is performed by an advisory committee of the board of directors of the GP OHS collaboration. The local committee was responsible for feedback to reporters and for follow-up measures when appropriate. Furthermore, reported incidents were analysed within 2 weeks instead of the usual every 2 months. The number of incidents in the GP OHS, using the LIRP, increased 16-fold compared with the GP OHSs using the CIRP. The implementation of a LIRP was associated with extra costs for administration and analysis. Reznek and Barton $^{30}$ evaluated the effectiveness of a standardised, non-punitive peer review process of incident reports in one ED compared to analysis of incident reports by a single reviewer. Relevant reports were peer reviewed each month by a committee of board certified physicians, and involved structured analysis and discussion of incidents with staff that participated in open peer review proceedings. The authors stated that the monthly frequency of reporting increased over time compared with 
Table 2 Quality assessment of studies with qualitative design

\begin{tabular}{|c|c|c|c|c|c|}
\hline & $\begin{array}{l}\text { Patterson } \\
\text { et }\left.a\right|^{35}\end{array}$ & $\begin{array}{l}\text { Patterson } \\
\text { et }\left.a\right|^{37 \star}\end{array}$ & $\begin{array}{l}\text { Flowerdew } \\
\text { et }\left.a\right|^{\beta 8 \star}\end{array}$ & $\begin{array}{l}\text { Jaynes } \\
\text { et } a l^{39 *}\end{array}$ & $\begin{array}{l}\text { Schull } \\
\text { et } a l^{36}\end{array}$ \\
\hline Question/objective sufficiently described? & 2 & 2 & 1 & 2 & 2 \\
\hline Study design evident and appropriate? & 2 & 2 & 2 & 2 & 2 \\
\hline Context for the study clear? & 2 & 2 & 2 & 2 & 2 \\
\hline $\begin{array}{l}\text { Connection to a theoretical framework/wider } \\
\text { body of knowledge? }\end{array}$ & 2 & 2 & 2 & 1 & 1 \\
\hline $\begin{array}{l}\text { Sampling strategy described, relevant and } \\
\text { justified? }\end{array}$ & 2 & 2 & 2 & 1 & 2 \\
\hline $\begin{array}{l}\text { Data collection methods clearly described } \\
\text { and systematic? }\end{array}$ & 1 & 2 & 1 & 1 & 2 \\
\hline $\begin{array}{l}\text { Data analysis clearly described and } \\
\text { systematic? }\end{array}$ & 1 & 1 & 1 & 0 & 2 \\
\hline $\begin{array}{l}\text { Use of verification procedure(s) to establish } \\
\text { credibility? }\end{array}$ & 0 & 2 & 2 & 1 & 1 \\
\hline Conclusions supported by the results? & 2 & 2 & 1 & 2 & 2 \\
\hline Reflexivity of the account? & 0 & 1 & 1 & 1 & 1 \\
\hline Total points & 14 & 18 & 15 & 13 & 17 \\
\hline Maximum points possible & 20 & 20 & 20 & 20 & 20 \\
\hline Summary score, in percentage & 70 & 90 & 75 & 65 & 85 \\
\hline
\end{tabular}

that of a control group of practitioners from outside the hospital $(\mathrm{p}=0.0019 ; \mathrm{p}<0.0001)$.

\section{Patient safety indicators}

Pham et $a l^{31}$ evaluated the usability of one indicator: patient ED returns within $72 \mathrm{~h}$ of prior visit. Findings did not support the use of $72 \mathrm{~h}$ returns as a safety indicator: patients who return to the ED within $72 \mathrm{~h}$ do not use more resources, are not more severely ill and do not have a higher hospital admission rate than those who had not been previously seen. Schull et $a l^{36}$ sought to develop a set of evidence-based quality of care indicators for EDs. An expert panel reached consensus on a set of 48 indicators of which six focused on the measurement of patient safety. Of these six patient safety indicators, four were classified as feasible based on the use of current national administrative databases (eg, Percentage of patients with headache discharged home from the ED who were admitted to hospital with subarachnoid haemorrhage in the subsequent 14 days). The two other indicators (ie, 'Percentage of central lines inserted in the ED that developed catheter-related bloodstream infections' and 'Percentage of intubated patients for whom end-tidal carbon dioxide was monitored'), could be feasibly measured with enhanced quality and completeness of data (eg, coding of injuries, medical interventions and time registrations) in existing database fields.

\section{Training of safety attitudes and skills}

Jones $e t a l^{32}$ evaluated the effect of a teamwork training method (TeamSTEPPS) on improved staff perception of safety culture within the ED. The training was given in a period of 4 weeks, educating staff on how to communicate safety concerns, and report errors and system failures. Video vignettes were used illustrating good communication-as well as barriers to communication-to facilitate group discussion. Participants used hand-outs with communication techniques for practice, both in class and after the training sessions. Findings showed no statistical difference of perceived safety culture before and after the training. Patterson $e t a l^{33}$ evaluated the effectiveness of multidisciplinary simulation-based training. Care providers learned techniques to prevent medical errors, develop resilience, and to improve situation awareness and closed loop communication. Via debriefing of video-based simulations and a videotaped clinical scenario, ED personnel were trained to recognise high risk situations and to use the acquired skills to prevent or decrease the impact of unexpected events and errors. The training resulted in a statistically significant increase of patient safety knowledge and attitudes of personnel. The time required to conduct the training reduced over time from 12 to $4 \mathrm{~h}$.

\section{Safety walk-rounds}

Shaw $e t a l^{34}$ evaluated the effectiveness of PSWs in one ED. PSWs were performed by a physician and two staff nurses, and lasted approximately $30 \mathrm{~min}$. Each PSW was conducted in the clinical area of the ED and included data collection on two of the following clinical quality improvement topics: (1) accuracy of weight and allergy documentation; (2) compliance with hand washing; (3) accuracy of medication orders, administration and documentation; (4) appropriateness of patient monitoring and alarm parameters/central monitoring; (5) reasons for prolonged length of stay $(>3 \mathrm{~h})$ and (6) patient/ family communication. Rounds were followed by a general discussion with ED staff on, for example, staff near-miss experiences and suggestions for improvement. 
Table 3 Study characteristics

\begin{tabular}{|c|c|c|c|c|c|c|c|}
\hline \multirow[t]{2}{*}{$\begin{array}{l}\text { First author } \\
\text { (year) (country) }\end{array}$} & \multirow[t]{2}{*}{ Design } & \multirow[t]{2}{*}{ Setting } & \multirow[t]{2}{*}{ Sample } & \multirow[t]{2}{*}{ Intervention } & \multicolumn{3}{|l|}{ Findings } \\
\hline & & & & & Effects & Psychometrics & Feasibility \\
\hline $\begin{array}{l}\text { Wolff (2002) } \\
\text { (Australia) }^{22}\end{array}$ & $\begin{array}{l}\text { Quasi-experimental } \\
\text { (BA) }\end{array}$ & ED $(n=1)$ & $\begin{array}{l}\text { Reviewed patient } \\
\text { medical records } \\
(\mathrm{n}=20050)\end{array}$ & $\begin{array}{l}\text { Incident reporting in addition } \\
\text { to standardised screening of } \\
\text { medical records on AEs }\end{array}$ & Reduced AEs* & NR & NR \\
\hline $\begin{array}{l}\text { Hendrie }(2007) \\
\text { (Australia) }\end{array}$ & Non-experimental & $\operatorname{ED}(n=1)$ & $\begin{array}{l}\text { Patient case histories } \\
(n=3332)\end{array}$ & AE screening & NR & Inter-rater reliability & Time† \\
\hline $\begin{array}{l}\text { Patterson (2012) } \\
(\text { (USA) })^{35}\end{array}$ & Non-experimental & $\begin{array}{l}E M S \\
(n=N R)\end{array}$ & $\begin{array}{l}\text { Patient case reports } \\
(\mathrm{n}=250)\end{array}$ & $\begin{array}{l}\text { AE identification and severity } \\
\text { rating method }\end{array}$ & NR & $\begin{array}{l}\text { Internal reliability; } \\
\text { construct validity }\end{array}$ & NR \\
\hline $\begin{array}{l}\text { Patterson (2014) } \\
(\text { USA })^{37}\end{array}$ & Non-experimental & $\begin{array}{l}\text { HEMS } \\
(n=N R)\end{array}$ & $\begin{array}{l}\text { Expert clinicians in } \\
\text { emergency medicine } \\
\text { and HEMS }(n=10)\end{array}$ & $\begin{array}{l}\mathrm{AE} \text { identification and severity } \\
\text { rating method }\end{array}$ & NR & $\begin{array}{l}\text { Content and face } \\
\text { validity }\end{array}$ & NR \\
\hline $\begin{array}{l}\text { Clunas (2009) } \\
\text { (Australia) }^{24}\end{array}$ & Non-experimental & $\operatorname{ED}(n=1)$ & $\begin{array}{l}\text { Reviewed patient } \\
\text { deaths }(n=303)\end{array}$ & $\begin{array}{l}\text { Audit of all deaths that } \\
\text { occurred within } 48 \mathrm{~h} \text { of ED } \\
\text { presentation in addition to } \\
\text { auditing all deaths that } \\
\text { occurred in the ED itself }\end{array}$ & NR & NR & Usabilitył \\
\hline $\begin{array}{l}\text { van Noord } \\
\text { (2010) (The } \\
\text { Netherlands) }\end{array}$ & Non-experimental & $\operatorname{ED}(n=31)$ & $\begin{array}{l}\text { Closed and settled } \\
\text { claim files }(n=47)\end{array}$ & $\begin{array}{l}\text { Root Cause Analysis using } \\
\text { PRISMA method }\end{array}$ & NR & $\begin{array}{l}\text { Inter-rater } \\
\text { reliability; face } \\
\text { validity }\end{array}$ & Time† \\
\hline $\begin{array}{l}\text { Patterson (2010) } \\
(\text { USA })^{26}\end{array}$ & Non-experimental & $\begin{array}{l}\text { EMS } \\
\text { agencies } \\
(n=3)\end{array}$ & $\begin{array}{l}\text { EMTs and paramedics } \\
(n=71)\end{array}$ & EMS-SAQ & NR & $\begin{array}{l}\text { Internal reliability; } \\
\text { construct validity }\end{array}$ & $\begin{array}{l}\text { Response } \\
\text { rate‡; user } \\
\text { friendliness }\end{array}$ \\
\hline $\begin{array}{l}\text { Patterson (2010) } \\
(\text { USA })^{27}\end{array}$ & Non-experimental & $\begin{array}{l}\text { EMS } \\
\text { agencies } \\
(n=61)\end{array}$ & $\begin{array}{l}\text { Care providers } \\
(\mathrm{n}=1595)\end{array}$ & EMS-SAQ & NR & $\begin{array}{l}\text { Inter-rater } \\
\text { reliability; face } \\
\text { validity }\end{array}$ & NR \\
\hline $\begin{array}{l}\text { Flowerdew } \\
(2012)(U K)^{38}\end{array}$ & Non-experimental & $E D(n=2)$ & NR & $\begin{array}{l}\text { Observational physician } \\
\text { (non-technical) skills } \\
\text { assessment }\end{array}$ & NR & $\begin{array}{l}\text { Face and content } \\
\text { validity }\end{array}$ & NR \\
\hline 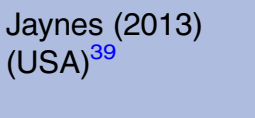 & Non-experimental & $\begin{array}{l}\text { EMS } \\
(n=N R)\end{array}$ & $\begin{array}{l}\text { EMS care providers } \\
(n=380)\end{array}$ & $\begin{array}{l}\text { EMS and HEMS working } \\
\text { relationship satisfaction } \\
\text { questionnaire }\end{array}$ & NR & $\begin{array}{l}\text { Internal reliability; } \\
\text { face, content and } \\
\text { construct validity }\end{array}$ & NR \\
\hline $\begin{array}{l}\text { Evans (2007) } \\
\text { (Australia) }^{28}\end{array}$ & $\begin{array}{l}\text { Quasi experimental } \\
\text { (NEG) }\end{array}$ & $\mathrm{ED}(\mathrm{n}=4)$ & $\begin{array}{l}\text { ED }(n=2) \text { attendances } \\
(n=66669) \text { with } \\
\text { intervention vs ED } \\
(n=2) \text { attendances } \\
(n=78 \text { 264) with usual } \\
\text { procedure }\end{array}$ & $\begin{array}{l}\text { Incident reporting programme } \\
\text { comprising intense staff } \\
\text { education, } 24 / 7 \text { reporting } \\
\text { options, changes in report } \\
\text { management and enhanced } \\
\text { feedback }\end{array}$ & Increased IRs* & NR & NR \\
\hline $\begin{array}{l}\text { Zwart (2011) } \\
\text { (The } \\
\text { Netherlands) })^{29}\end{array}$ & $\begin{array}{l}\text { Quasi experimental } \\
\text { (NEG) }\end{array}$ & $\begin{array}{l}\text { GP OHS } \\
(n=3)\end{array}$ & $\begin{array}{l}\text { GP OHS with } \\
\text { intervention }(n=1) ; G P \\
\text { OHS with usual } \\
\text { procedure }(n=2)\end{array}$ & $\begin{array}{l}\text { Local incident-reporting vs } \\
\text { centralised incident reporting } \\
\text { (usual procedure) }\end{array}$ & $\begin{array}{l}\text { Increased IRs; } \\
\text { increased IR } \\
\text { types }\end{array}$ & NR & Timeł; costs $\dagger$ \\
\hline
\end{tabular}




\begin{tabular}{|c|c|c|c|c|c|c|c|}
\hline \multirow[t]{2}{*}{$\begin{array}{l}\text { First author } \\
\text { (year) (country) }\end{array}$} & \multirow[t]{2}{*}{ Design } & \multirow{2}{*}{ Setting } & \multirow[t]{2}{*}{ Sample } & \multirow{2}{*}{ Intervention } & \multicolumn{3}{|l|}{ Findings } \\
\hline & & & & & Effects & Psychometrics & Feasibility \\
\hline $\begin{array}{l}\text { Reznek (2014) } \\
(\text { (USA) })^{30}\end{array}$ & $\begin{array}{l}\text { Quasi experimental } \\
\text { (ITS) }\end{array}$ & $\operatorname{ED}(n=1)$ & IRs $(n=314)$ & $\begin{array}{l}\text { Standardised non-punitive } \\
\text { peer review of IRs }\end{array}$ & $\begin{array}{l}\text { Increased } \\
\text { monthly } \\
\text { frequencies of } \\
\text { IRs }^{*}\end{array}$ & NR & NR \\
\hline $\begin{array}{l}\text { Schull }(2011) \\
\text { (Canada) }^{36}\end{array}$ & Non-experimental & ED $(n=N R)$ & $\begin{array}{l}\text { Candidate indicators } \\
(n=170)\end{array}$ & Patient safety indicators & NR & Face validity & Usability \\
\hline $\begin{array}{l}\text { Pham (2011) } \\
(\text { USA })^{31}\end{array}$ & Non-experimental & $\operatorname{ED}(n=1)$ & $\begin{array}{l}\text { Patients seen in the } \\
\text { ED within } 72 \mathrm{~h} \text { of prior } \\
\text { visit }(n=6858) \text { and } \\
\text { patients not seen in } \\
\text { the ED within } 72 \mathrm{~h} \\
(\mathrm{n}=211321)\end{array}$ & Patient safety indicator & NR & NR & Usability† \\
\hline $\begin{array}{l}\text { Jones (2013) } \\
(\text { USA) }\end{array}$ & Non-experimental & $\operatorname{ED}(n=2)$ & Care providers $(n=60)$ & $\begin{array}{l}\text { Teamwork training on patient } \\
\text { safety (TeamSTEPPS) }\end{array}$ & $\begin{array}{l}\text { Positive change } \\
\text { in safety culture } \\
\text { perception }\end{array}$ & NR & NR \\
\hline $\begin{array}{l}\text { Patterson (2013) } \\
(\text { USA) }\end{array}$ & $\begin{array}{l}\text { Quasi experimental } \\
\text { (ITS) }\end{array}$ & $\begin{array}{l}\text { Paediatric } \\
\text { ED }(n=1)\end{array}$ & $\begin{array}{l}\text { Care providers } \\
(n=151)\end{array}$ & $\begin{array}{l}\text { Multidisciplinary } \\
\text { simulation-based training }\end{array}$ & $\begin{array}{l}\text { Increased staff } \\
\text { safety } \\
\text { knowledge*; } \\
\text { increased staff } \\
\text { safety attitude* }\end{array}$ & NR & Timeł \\
\hline $\begin{array}{l}\text { Shaw (2006) } \\
\left(\text { USA) }{ }^{34}\right.\end{array}$ & Non-experimental & $\begin{array}{l}\text { Paediatric } \\
\text { ED }(n=1)\end{array}$ & Staff $(n=99)$ & $\begin{array}{l}\text { Unit-based Patient Safety } \\
\text { Walk-rounds }\end{array}$ & $\begin{array}{l}\text { Increased IRs; } \\
\text { increased hand } \\
\text { hygiene } \\
\text { compliance }\end{array}$ & NR & NR \\
\hline
\end{tabular}


Subsequently, the ED Patient Safety Committee (ie, directors, managers) reviewed results and incident reports. An email was sent to all staff regularly, to inform on positive outcomes and needs for improvement. Study findings showed $44 \%$ increase of medication near-miss incident reports and 23\% overall increase in hand hygiene compliance within the ED.

\section{DISCUSSION}

To the best of our knowledge, this is the first systematic review of studies evaluating the effects, reliability, validity and feasibility of interventions to improve the governance of patient safety in emergency care. Our review highlights the lack of evidence on effective safety governance strategies in emergency care settings, particularly in the field of prehospital emergency care. Only four studies examining an intervention in EDs and GP OHS reported statistically significant effects on reduced AEs, an increase of reported incidents, and an increase of patient safety attitudes and knowledge among care providers. The validity, reliability and feasibility of interventions varied greatly. Moreover, the information provided in terms of time investment, costs and usability, was limited.

We identified two types of interventions that showed to be effective in improving the governance of patient safety within organisations. First of all, simulation-based patient safety training proved to be an effective intervention for improving the patient safety culture and safe medical practice in the ED. These findings correspond with the literature on medical education and training. Simulation-based training is increasingly valued as an effective method to enhance safety knowledge and behaviour of providers and healthcare teams, in addition to didactic education methods. ${ }^{40}{ }^{41}$ In a controlled setting, care providers can experience infrequent and unexpected events, and learn to practice resilient behaviour. ${ }^{42}$ This is especially important in a high-risk sector such as emergency care. Second, the use of welldesigned incident reporting systems leads to an increase of incidents reported by GP OHS and ED staff, which is an important source of data for executives to use for monitoring safety risks. Effective incident reporting systems shared the following components: (1) education of staff on the importance and the learning purpose of reporting; (2) multiple and constantly available reporting options for staff; (3) a short reporting form to minimise the burden of reporting and (4) structural feedback by presenting descriptive statistics, findings of incident root-cause analyses and improvement actions. These findings are supported by other publications on successful incident reporting systems. ${ }^{43-46}$ In a setting such as emergency care, where providers constantly have to deal with time pressure, it is important that sufficient resources for effective and efficient reporting are available. Additionally, a non-punitive reporting system is imperative for a culture of self-reporting to thrive. ${ }^{47}$
Interestingly, the effective incident reporting systems had different approaches towards anonymous reporting and the management of reports. One system had the ability for care providers to report anonymously, and anonymous reports were validated and followed-up only by the patient safety manager. This is consistent with previous studies suggesting that anonymous reporting and validation of reports by an independent party can increase the quality of reporting by care providers. ${ }^{48} 49$ In contrast, the other system invited care providers to participate in a non-anonymous peer review process that involved analysis and structured discussion of incident reports submitted to ED physician leadership. This suggests that anonymity of reporting and management of incident reports by an independent party may not be necessary if an incident reporting and review process is perceived to be safe.

No effective interventions were found that aim to monitor or improve patient safety in the chain of emergency care. This is a disturbing finding considering the high number of patient transitions and the unique challenges to safe handoffs between EMS organisations. ${ }^{5-7}$

Our hope is that this systematic review will act as a stimulus to gather more evidence on safety governance improvements in the field of emergency care. Characteristics of the interventions included in this review (eg, anonymous reporting and validation of reports by an independent party) could provide useful input for the design of an effective tool to govern patient safety in EMS organisations and hospital-based EDs. However, at the moment, executives cannot rely on several evidence-based strategies to govern patient safety within their organisation and in the chain of emergency care. A variety of established and effective tools are used in other healthcare domains and high-reliability sectors, such as the aviation and chemical industry. For example, safety indicators ${ }^{50}$ patient safety dashboards and checklists, ${ }^{51}{ }^{52}$ prospective risk analysis techniques (eg, Bow-tie, Failure Mode Effect Analysis) ${ }^{53}$ and safety audits. ${ }^{54}{ }^{55}$ These strategies need to be evaluated on effectiveness and feasibility in studies with multiple (types of) EMS organisations as study sample, a control group, and uniform and valid outcome measures. Executives, quality officers and researchers should therefore keep in mind that these interventions need to correspond with the organisation's current patient safety stage ${ }^{56}$ For example, the use of risk surveillance and educational interventions are doomed to fail without a culture of openness about errors among staff, and a proactive attitude towards safety improvement.

\section{Review limitations}

Our review has several limitations. First, the heterogeneity in the selected studies in terms of design, aims, intervention activities, sample, outcome measurements and presented outcomes prevented us from performing quantitative meta-analyses. Second, we experienced difficulties with including relevant studies, because most studies did not explicitly address if interventions were 
meant to improve safety governance at the executive level (ie, board of directors), or at the middle or lower management level (ie, heads of department, unit leaders) or both. Third, the outcome measures used by the studies may not reflect the impact of safety governance activities. For example, a reduced AE rate may be caused by factors other than an improved reporting system. Moreover, an increase of incident reports may also be an indicator of over-reporting by care providers. There are no uniform and clear criteria for measuring effective governance of patient safety in healthcare organisations. Therefore, the effects found need to be interpreted with caution. Fourth, evaluations with an observational design dominated the studies we identified. The design of these studies limits the ability to draw firm conclusions on the effectiveness of individual interventions. Fifth, the effectiveness and feasibility of reviewed interventions may relate to a specific medical or demographical setting. Two-thirds of the studies included in this review were performed in one or more EDs. More than a third of the included studies were conducted in a single organisation. Sixth, restricting the literature search to studies published in the English and Dutch languages may have introduced a study selection bias based on language. However, we did not find non-English publications that met our inclusion criteria.

\section{CONCLUSION}

Simulation-based training and incident reporting systems with a focus on reducing the fear of reporting, reporting burden, and structural and systematic feedback, are promising interventions to improve the governance of patient safety in emergency care. However, the weak study designs, the lack of valid outcome measures and information on feasibility hinder the demonstration of robust evidence to support these interventions. Promising interventions for the governance of patient safety in the chain of emergency care are absent. Further research evaluating established governance tools on effectiveness and feasibility from other sectors within emergency care organisations is warranted.

\section{Author affiliations}

${ }^{1}$ Regional Emergency Healthcare Network, Radboud University Medical Center, Nijmegen, The Netherlands

${ }^{2}$ Radboud University Medical Center, Scientific Institute for Quality of Healthcare (IQ healthcare), Nijmegen, The Netherlands

${ }^{3}$ Faculty of Health and Social Studies, Department of Emergency and Critical Care, HAN University of Applied Sciences, Nijmegen, The Netherlands ${ }^{4}$ Faculty of Health Science, NIHR CLAHRC Wessex, University of Southampton, Southampton, UK

Contributors GH, SB and LS were involved in conception and design of the study. GH and SB were responsible for data acquisition. GH, SB and TB analysed and interpreted the data. GH, SB and LS drafted the manuscript, which was critically revised for important intellectual content by all the authors.

Funding This study was funded (grant number $80-83200-98-037$ ) by the Netherlands Organisation for Health Research and Development (ZonMw).

Competing interests None declared.
Provenance and peer review Not commissioned; externally peer reviewed.

Data sharing statement No additional data are available.

Open Access This is an Open Access article distributed in accordance with the Creative Commons Attribution Non Commercial (CC BY-NC 4.0) license, which permits others to distribute, remix, adapt, build upon this work noncommercially, and license their derivative works on different terms, provided the original work is properly cited and the use is non-commercial. See: http:// creativecommons.org/licenses/by-nc/4.0/

\section{REFERENCES}

1. Callender AN, Hastings DA, Hemsley MC, et al. Corporate Responsibility and Health Care Quality: A Resource for Health Care Boards of Directors. 2007. https://oig.hhs.gov/fraud/docs/ complianceguidance/CorporateResponsibilityFinal\%209-4-07.pdf (accessed 23 Feb 2015).

2. Goeschel C, Wachter R, Pronovost P. Responsibility for quality improvement and patient safety: hospital boards and medical staff leadership challenges. Chest 2010;138:171-8.

3. Millar R, Mannion R, Freeman T, et al. Hospital board oversight of quality and patient safety: a narrative review and synthesis of recent empirical research. Milbank Q 2013;91:738-70.

4. Patterson PD, Arnold RM, Abebe K, et al. Variation in emergency medical technician partner familiarity. Health Serv Res 2011;46:1319-31.

5. Owen C, Hemmings $\mathrm{T}$, Brown T. Lost in translation: maximizing handover effectiveness between paramedics and receiving staff in the emergency department. Emerg Med Australas 2009;21:102-7.

6. van Leijen-Zeelenberg JE, van Raak AJ, Duimel-Peeters IG, et al. Interprofessional communication failures in acute care chains: how can we identify the causes? J Interprof Care 2015;29:320-30.

7. Meisel ZF, Shea JA, Peacock NJ, et al. Optimizing the patient handoff between emergency medical services and the emergency department. Ann Emerg Med 2015;65:310-17.

8. Forster AJ, Rose NG, van Walraven C, et al. Adverse events following an emergency department visit. Qual Saf Health Care 2007;16:17-22.

9. Calder LA, Forster A, Nelson M, et al. Adverse events among patients registered in high-acuity areas of the emergency department: a prospective cohort study. CJEM 2010;12:421-30.

10. Stang AS, Wingert AS, Hartling $L$, et al. Adverse events related to emergency department care: a systematic review. PLOS ONE 2013;8:e74214.

11. Bigham BL, Buick JE, Brooks SC, et al. Patient safety in emergency medical services: a systematic review of the literature. Prehosp Emerg Care 2012;16:20-35.

12. MacDonald RD, Banks BA, Morrison M. Epidemiology of adverse events in air medical transport. Acad Emerg Med 2008;15:923-31.

13. Huibers L, Smits M, Renaud V, et al. Safety of telephone triage in out-of-hours care: a systematic review. Scand J Prim Health Care 2011;29:198-209.

14. Cushman JT, Fairbanks RJ, O'Gara KG, et al. Ambulance personnel perceptions of near misses and adverse events in pediatric patients. Prehosp Emerg Care 2010;14:477-84.

15. Smits M, Groenewegen PP, Timmermans DR, et al. The nature and causes of unintended events reported at ten emergency departments. BMC Emerg Med 2009:9:16.

16. Bismark MM, Studdert DM. Governance of quality of care: a qualitative study of health service boards in Victoria, Australia. BMJ Qual Saf 2014;23:474-82.

17. Parand A, Dopson S, Renz A, et al. The role of hospital managers in quality and patient safety: a systematic review. BMJ Open 2014;4: e005055.

18. Hastings SE, Armitage GD, Mallinson S, et al. Exploring the relationship between governance mechanisms in healthcare and health workforce outcomes: a systematic review. BMC Health Serv Res 2014;14:479.

19. Phillips CB, Pearce CM, Hall S, et al. Can clinical governance deliver quality improvement in Australian general practice and primary care? A systematic review of the evidence. Med J Aust 2010;193:602-7.

20. Moher D, Liberati A, Tetzlaff J, et al. Preferred reporting items for systematic reviews and meta-analyses: the PRISMA statement. Ann Intern Med 2009;151:264-9.

21. Kmet LM, Lee RC, Cook LS. Standard quality assessment criteria for evaluating primary research papers from a variety of fields. Edmonton: Alberta Heritage Foundation for Medical Research, 2004. 
22. Wolff A, Bourke J. Detecting and reducing adverse events in an Australian rural base hospital emergency department using medical record screening and review. Emerg Med J 2002;19:35-40.

23. Hendrie J, Sammartino L, Silvapulle MJ, et al. Experience in adverse events detection in an emergency department: incidence and outcome of events. Emerg Med Australas 2007;19:16-24.

24. Clunas S, Whitaker R, Ritchie N, et al. Reviewing deaths in the emergency department: deaths in the department or deaths within 48 h. Emerg Med Australas 2009;21:117-23.

25. van Noord I, Eikens MP, Hamersma AM, et al. Application of root cause analysis on malpractice claim files related to diagnostic failures. Qual Saf Health Care 2010;19:e21.

26. Patterson PD, Huang DT, Fairbanks RJ, et al. The emergency medical services safety attitudes questionnaire. Am J Med Qual 2010;25:109-15.

27. Patterson PD, Huang DT, Fairbanks RJ, et al. Variation in emergency medical services workplace safety culture. Prehosp Emerg Care 2010;14:448-60.

28. Evans SM, Smith BJ, Esterman A, et al. Evaluation of an intervention aimed at improving voluntary incident reporting in hospitals. Qual Saf Health Care 2007:16:169-75.

29. Zwart DL, Van Rensen EL, Kalkman CJ, et al. Central or local incident reporting? A comparative study in Dutch GP out-of-hours services. Br J Gen Pract 2011;61:183-7.

30. Reznek MA, Barton BA. Improved incident reporting following the implementation of a standardized emergency department peer review process. Int J Qual Health Care 2014;26:278-86.

31. Pham JC, Kirsch TD, Hill PM, et al. Seventy-two-hour returns may not be a good indicator of safety in the emergency department: a national study. Acad Emerg Med 2011;18:390-7.

32. Jones F, Podila P, Powers C. Creating a culture of safety in the emergency department: the value of teamwork training. J Nurs Adm 2013;43:194-200.

33. Patterson MD, Geis GL, LeMaster T, et al. Impact of multidisciplinary simulation-based training on patient safety in a paediatric emergency department. BMJ Qual Saf 2013;22:383-93.

34. Shaw KN, Lavelle J, Crescenzo K, et al. Creating Unit-Based Patient Safety Walk-Rounds in a Pediatric Emergency Department. Clin Ped Emerg Med 2006;7:231-7.

35. Patterson PD, Weaver MD, Abebe $\mathrm{K}$, et al. Identification of adverse events in ground transport emergency medical services. Am J Med Qual 2012;27:139-46.

36. Schull MJ, Guttmann A, Leaver CA, et al. Prioritizing performance measurement for emergency department care: consensus on evidence-based quality of care indicators. CJEM 2011;13:300-9, E28-43.

37. Patterson PD, Lave JR, Martin-Gill C, et al. Measuring adverse events in helicopter emergency medical services: establishing content validity. Prehosp Emerg Care 2014;18:35-45.

38. Flowerdew $\mathrm{L}$, Brown $\mathrm{R}$, Vincent $\mathrm{C}$, et al. Development and validation of a tool to assess emergency physicians' nontechnical skills. Ann Emerg Med 2012;59:376-85.
39. Jaynes CL, Cook P, Farmer R, et al. Assessing satisfaction and quality in the EMS/HEMS working relationship. Air Med $J$ 2013;32:338-42.

40. Harvey A, Nathens AB, Bandiera G, et al. Threat and challenge: cognitive appraisal and stress responses in simulated trauma resuscitations. Med Educ 2010;44:587-94.

41. Bong CL, Lightdale JR, Fredette ME, et al. Effects of simulation versus traditional tutorial-based training on physiologic stress levels among clinicians: a pilot study. Simul Healthc 2010;5:272-8.

42. Lateef F. Simulation-based learning: Just like the real thing. J Emerg Trauma Shock 2010;3:348-52.

43. Stump LS. Re-engineering the medication error-reporting process: removing the blame and improving the system. Am J Health System Pharm 2000;57(Suppl 4):S10-17.

44. Benn J, Koutantji M, Wallace L, et al. Feedback from incident reporting: information and action to improve patient safety. Qual Saf Health Care 2009;18:11-21.

45. Gandhi TK, Graydon-Baker E, Huber CN, et al. Closing the loop: follow-up and feedback in a patient safety program. Jt Comm J Qual Patient Saf 2005;31:614-21.

46. Hartnell N, MacKinnon N, Sketris I, et al. Identifying, understanding and overcoming barriers to medication error reporting in hospitals: a focus group study. BMJ Qual Saf 2012;21:361-8.

47. Snijders C, Kollen BJ, van Lingen RA, NEOSAFE Study Group. Which aspects of safety culture predict incident reporting behavior in neonatal intensive care units? A multilevel analysis. Crit Care Med 2009;37:61-7.

48. Leape LL. Reporting of adverse events. N Engl J Med 2002;347:1633-8.

49. Clarke JR. How a system for reporting medical errors can and cannot improve patient safety. Am Surg 2006;72:1088-91; discussion 1126-48.

50. Rosen AK, Zhao S, Rivard P, et al. Tracking rates of patient safety indicators over time: lessons from the Veterans Administration. Med Care 2006;44:850-61.

51. Pugh M, Reinertsen J. Reducing harm to patients: using patient safety dashboards at the board level. Healthc Exec 2007;22:64-5

52. Goeschel CA, Holzmueller CG, Pronovost PJ. Hospital Board Checklist to improve culture and reduce central line associated bloodstream infections. Jt Comm J Qual Patient Saf 2010;36:525-8.

53. Hover AR, Sistrunk WW, Cavagnol RM, et al. Effectiveness and cost of failure mode and effects analysis methodology to reduce neurosurgical site infections. Am J Med Qual 2014;29:517-21.

54. Ursprung R, Gray JE, Edwards WH, et al. Real time patient safety audits: improving safety every day. Qual Saf Health Care 2005; 14:284-9.

55. Ivers N, Jamtvedt G, Flottorp S, et al. Audit and feedback: effects on professional practice and healthcare outcomes. Cochrane Database Syst Rev 2012;6:CD000259.

56. Volpp KG, Grande D. Residents' suggestions for reducing errors in teaching hospitals. N Engl J Med 2003;348:851-5. 